\title{
Organizational Communication Audits: Assessing Core Communication Competencies Within The Organization
}

\author{
Robert L. Minter, Ph.D., Walsh College, USA
}

\begin{abstract}
This paper discusses how the utilization of communication audits can enhance an organization's ability to improve its internal communication. Suggestions are provided for developing and administering micro and macro communication audits.
\end{abstract}

Keywords: Organization communication audits, communication audits, assessing organizational communication competencies, vertical and lateral communication, managerial leadership and communication.

\section{BACKGROUND OF ORGANIZATIONAL COMMUNICATION}

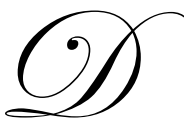

uring the past fifty years, the emergence of a discipline within the United States, referred to as organizational communication, has developed into a unique field of its own. It is a field combining both behavioral science theories with communication theories to assess and improve communication climates in organizations. Being an eclectic discipline, it utilizes concepts from many fields such as psychology, sociology, anthropology, general semantics, systems theory, industrial relations, and organizational theory.

The primary focus of organization communication research is the study of communication channels (both formal and informal), communication attitudes, interpersonal communication behavior, and overall communication culture/subcultures within hierarchical structures

The term "communication" is often misused by many managers when attempting to identify work-related issues as "communication" problems. Mislabeling issues within the work setting by referring to them as communication problems can easily create an environment where managers fall into the trap of identifying and solving the wrong problem. The cause of the problem may not be one of communication, but of faulty work processes, inappropriate policies, or other performance-related issues. This also can result in developing ineffective human relationships and leadership style practices within the organization.

Surveys are abundant that ask managers what skills are important for employees, managers and successful leaders to have in the firm. Generally, items that lead the list of top-level skills are those often referred to as "soft skills" (e.g., oral communication skills, listening, writing, reading, problem solving, people skills.). Surprisingly, although extremely important, the "hard skills" (e.g., technical knowledge and skills) seldom lead the list. Someone once said that "Soft skills are the hard skills to acquire to become an effective leader."

Employees can be trained to become more effective by improving upon their communication soft skills. However, if a firm only emphasizes communication/human relations skills training, it will discover that soft skills training by itself will not significantly change the organization's communication climate or culture. Many employee training budgets are misspent by promoting interpersonal communication and human relations training without realizing, or focusing on, the underlying communication barriers that need to be addressed within the organization.

Any mention of communication attitudes, behaviors, and skills leads to a discussion of human relations' attitudes, behaviors and skills. Communication and human relations concepts are so closely related as to be almost synonymous. It is extremely difficult to study one without involving the other. 
Developing an effective human relation's climate is perhaps the most important and the most difficult skill of management; the philosophy and techniques of communication are an essential part of it. One management consultant, some years ago, went so far as to declare:

It is impossible to have human relations without communications, and vice versa.

Separation of the two comes in, however, when the desire for improvement enters.

While communications can be improved without improving human relations, human relations cannot be improved without improving communication.

Hence, unimpeded two-way vertical and horizontal communication is commonly regarded as essential to the health of the organization. This, however, is a difficult task for many organizations to accomplish, because by its very nature communication is largely a human problem subject to human foibles, often creating unintended 'human relations' problems. ${ }^{.}$

Communication research in organizations typically involves investigating such phenomena as employee perceptions, attitudinal constructs, "semantic" and informational distance," and similar variables pertaining to the relationship between interpersonal communication and organizational effectiveness. For at least the past fifty years, theorists and researchers have discovered that many managers lack sufficient commitment, sensitivity, training or diagnostic ability to be able to identify employee communication needs. ${ }^{2}$

With the advent of the new communication technologies emerging these past two to three decades, developing face-to-face human relations contact at the interpersonal communication level have deteriorated. Emphasis on high speed communication presents new interpersonal communication challenges to the practicing manager (e.g., cell phones, blackberries, internet, email, twitter, and other social networking media).

Observations of employee daily communication practices will illustrate that there is perhaps an overdependence on using high speed communication technology in the work setting. As a consequence, it can ( and does) reduce the amount of interpersonal face-to-face communication contact among employees. Over-reliance in using technology to communicate can easily result in dysfunctional consequences for the organization, and can easily promote addictive techno- behavior among employees. Those who become addicts of technology tend to relate less to others on the interpersonal level and spend little time developing face-to-face communication relationships. Over-reliance on using technology to communicate can negatively impact human relations development and sensitivity that needs to be nurtured among managers and their employees on vertical, horizontal and diagonal levels within the formal and informal communication structures of the organization.

Gibb proposed that such failures in communication sensitivity can bring about "defensive communication on the part of both senders and receivers, leading in turn to a wide variety of message distortions and even paranoia among employees. With today's communication technology environment, and economic threats to employee job security, conditions for creating defensive communication climates are probably on the increase."”

Because of these conditions, it is extremely important that organizations be sensitive to the communication needs and perceptions of all its employees at every level. One way of developing this organizational sensitivity is by utilizing periodic communication audits in the firm. ${ }^{4}$ Many of the communication audit concepts discussed here were developed from dissertation research under the direction of the late Dr. W. Charles Redding, Professor of Organizational Communication. Doctoral research in organizational communication from Purdue University is often referred to as the Purdue Studies in organizational communication.

Within the United States, Dr. Redding is often referred to as the "father" of organizational communication theory. Due to his contributions, and those of his graduate students, a growing body of organizational communication theory and doctoral research has emerged from Purdue's doctoral program in organizational communication. These contributions have also provided theoretical concepts for others to pursue in their organization communication research endeavors. 
The objective of this article is to provide a model that can assist one in developing a communication audit to evaluate communicate climates within organizational structures. This can be done by utilizing seven organizational communication core competencies that have emerged from the Purdue studies: ${ }^{5}$

\section{ORGANIZATIONAL COMMUNICATION CORE COMPETENCIES}

Transformational leaders within organizational settings desire to create effective vertical and lateral communication interchanges among all employees. They realize that the overall effectiveness of organizations they lead depend on the ability of the firm to adapt to change and to maintain relevancy in the marketplace. To be effective, with today's dependence on high speed communication, the millennial leader must create and sustain an open communication climate at all levels. To do this, however, the transformational leader needs to be knowledgeable of organizational communication core competencies. The following competencies should periodically be audited to determine the ongoing health of the communication climate within the departments of the organization:

$\begin{array}{ll}\text { - } & \text { Influence } \\ \text { - } & \text { Feedback Responsiveness } \\ \text { - } & \text { Permissiveness } \\ \text { - } & \text { Interdependence } \\ \text { - } & \text { Reward for Communicating } \\ & \text { Trust. }\end{array}$

Based on the above communication core competencies, the following model has been developed by this author. For each of the seven core communication competencies, there are three dimensions of communication that can be measured. This model provides an opportunity for the researcher to measure vertical (upward, downward) and lateral communication behavior utilizing a twenty- one cell matrix.

Exhibits 1 and 2 define and provide an overview of the dimensions of vertical and lateral communication that go beyond effective writing and speaking skills. Utilizing these dimensions to audit an organization's communication climate can assist management in exploring its organization's communication culture. The audit experience will present a driving force for management to evaluate and improve upon its communication strengths and weaknesses, communication strategies and existing communication barriers.

Organizational communication audits can be performed in small workshop settings or administered on a larger scale within selected segments of an organization: 1) The former is less costly and can utilize the Mini Communication Audit to promote awareness and discussion among workshop attendees. The Mini Audit can be used to develop immediate sensitivity among participants to the tools available to audit a firm's communication culture; 2) Administering a communication audit on a larger scale within the organization will provide more accurate and in-depth analysis of the firm's communication practices. This, of course, is more time consuming and more costly than employing the Mini Audit in workshop settings.

\section{THE MINI COMMUNICATION AUDIT EXPERIENCE}

The overall purpose of the Mini Audit workshop experience is to: 1) develop an awareness among participants that there is more to improving communication within the firm than just focusing on the soft communication skills; 2) develop an awareness for each participant of the organization's strengths and deficiencies regarding its core communication competencies (as addressed in Exhibits 1 and 2); 3) provide an opportunity for participants to share among themselves their ideas to improve communication within their organization; 4) provide participants with concepts and suggestions for improving internal communication that they can share with their respective employers.

Information contained in Exhibits 1 and 2 can be utilized very efficiently in short-term workshop settings where organizational communication is being discussed. Providing participants an opportunity to engage in a "high 
speed communication audit" in a workshop setting can be helpful in directing participants to look at organizational communication issues with a new perspective.

\section{Workshop Experience}

The following procedure is explained for those who wish to administer the audit within a seminar or workshop experience. For example, managers in a workshop setting are introduced to the concepts in Exhibit 1 by the facilitator and are asked to move through the following experiential phases.

Phase 1. The facilitator provides participants with a copy of Exhibit 1 and explains the concepts contained within it, being very clear that for every competency listed in the left- hand column there are three communication dimensions to consider and to evaluate. In doing so they must select a unit of focus when applying the audit (e.g., department, other work unit, or entire organization.) Explanation and discussion of the concepts are needed before participants can complete the audit (Exhibit 2). The audit should not be given to the participants until the facilitator feels comfortable that the participants understand Exhibit I concepts.

Phase 2. Participants are asked individually to answer the Organization Communication Climate Profile (OCCP, Exhibit 2) using the descriptions of the core competencies provided in Exhibit 1. Upon completion of the OCCP, they are asked to determine their individual mean scores for each vertical dimension. The results of each column score in Exhibit 2 provide participants with a perceptual snapshot of their overall communication satisfaction for each of the three communication dimensions as they relate to their own work environment.

The workshop audit experience is always more effective if participants from the same organization can agree to select a common area of focus (e.g., department, work unit) before they take the audit. Trying to obtain common agreement on a specific area of focus among ten to twenty participants representing non-homogeneous organizations may be difficult to accomplish. Arriving at a common focus is many times easier if the workshop consists of a homogeneous group of participants. However, attempting to obtain agreement before the audit is administered to non-homogeneous participants regarding common "areas of focus" is not necessary in order to having a meaningful discussion of their audit results..

Phase 3. This is the Phase where participants share and discuss their audit results. Sharing can be done within small breakout groups of two to three individuals, or done on an individual sharing basis with the entire class. The preferred dynamic is to utilize the small group sharing model. As a suggestion, if the workshop consists of a nonhomogeneous participant mix, the facilitator might ask individuals from similar industries or non-profit organizations to form discussion groups that reflect their business/organizational sectors.

This Phase concludes by having a spokesperson from each group feedback what they discovered as communalities and differences in their perceptions of audit outcomes and issues brought out by the audit.

Phase 4. Individuals are then asked to identify two organizational competencies and one respective dimension for each where they would like to see improvement, and provide ideas for resolving those issues within their focused area identified in Phase I. Time permitting, the facilitator should encourage participants to share with the other participants their perceptions and ideas for improving communication.

The amount of time to administer the Mini Communication Audit will vary based on the purpose of the workshop and other topics that need to be discussed. At a minimum, no less than sixty minutes should be dedicated for the mini audit to be completed and discussed. With time permitting, participants will be able to profile their communication environment and offer suggestions for overcoming communication barriers that may exist within their respective work units.

\section{Coaching vs. Self-Directed Approach}

There may be instances where a single individual with managerial responsibility would like to take the high speed Mini Audit to gain insight into his/her communication style. This can be done by utilizing either the coaching 
or self-directed approach: 1) The coaching approach is where the consultant personally guides the individual through the total audit process, involving the data collection and data analytics. 2) The self-directed approach is where the manager administers the material to employees/peers on his/her own without the assistance of a coach or mentor.

The coaching approach is the most preferred as a change agent tool and works best if other data can be provided to the manager which reflects employee perceptions of the manager's communication style. The selfdirected approach is not recommended for many reasons that should be obvious to the reader.

Quite often, the insights gained from managers participating in a workshop communication audit experience will lead to their recommending to their superiors that an organization-wide communication audit should be considered.

\section{DEVELOPING THE MACRO COMMUNICATION AUDIT}

For organizations desiring a large scale communication audit, the information contained in Exhibit 1 can provide the model for researching the employee perceptions of the firm's communication climate at any unit level (e.g., department, division, organization-wide, etc).

Competencies and dimensions of communication identified in Exhibit 1 can provide the structure for developing a bank of questions to be considered in the development of the Macro Communication Audit. Examples of questions to assess the seven competencies and their respective dimensions are illustrated below:

\section{Competency: Influence}

Dimension: Downward Influence

How much influence do you think you have in trying to change the work attitudes of those who report to you? (Almost Always, Very Often, About Half the Time, Occasionally, Never or Almost Never)

How much influence do you feel you have in changing the performance behavior of employees working for you? (AA, VO, 1/2, O, NAN)

\section{Dimension: Upward Influence}

How influential do you think you are with your immediate supervisor in getting your ideas accepted? (AA, $\mathrm{VO}, 1 / 2, \mathrm{O}, \mathrm{NAN})$

To what degree to do you feel your company allows its employees at all levels to speak their minds to their bosses about such things as company policy, work problems, dislikes about supervision - about anything? $(\mathrm{AA}, \mathrm{VO}, 1 / 2, \mathrm{O}, \mathrm{NAN})$

\section{Dimension: Lateral Influence}

To what degree do you feel you can freely share your ideas, concerns and opinions on work-related issues with your peers within your Department? (AA, VO, $1 / 2, \mathrm{O}, \mathrm{NAN}$ )

How often do you find occasion to discuss work-related problems with your peers in other departments? $(\mathrm{AA}, \mathrm{VO}, 1 / 2, \mathrm{O}, \mathrm{NAN})$

\section{Competency: Feedback Receptiveness}

Dimension: Downward Receptiveness

How would you rate the value of feedback obtained from those reporting to you, to alter your thinking (or 
direction) after you've made a decision? (Extremely High Value, High Value, Moderate Value, Low Value, Little or No Value)

How would you rate the communication climate in your organization in terms of encouraging subordinate levels to provide feedback to previously communicated strategic thinking? (Extremely High Level of Encouragement, High level of Encouragement, Moderate Level of Encouragement, Low level of Encouragement, Little or No Encouragement)

\section{Dimension: Upward Receptiveness}

Generally, how comfortable do you feel sharing your thoughts and concerns about the environment in which you're working with your immediate supervisor? "(Feel Extremely Comfortable, Feel Very Comfortable, Feel Moderately Comfortable, Feel Somewhat Uncomfortable, Feel Very Uncomfortable)

To what degree does your immediate supervisor encourage his/her employees to provide feedback on work-related concerns? (Extremely high Level of Encouragement, High level of Encouragement, Modest Level, Low level of Encouragement, Little or No Encouragement?)

\section{Dimension: Lateral Receptiveness}

How open are your peers in receiving information from you that might impact the way they are carrying out their work responsibilities? (Extremely Open, Very Open, Moderately Open, Low Openness, Little or No Openness)

How willing are your peers in sharing work related information that will help you become more effective on your job? (Extremely Willing, Very Willing, Moderately Willing, Low Willingness, Little or No Willingness).

\section{Competency: Permissiveness}

Dimension: Downward Permissiveness

To what degree do you provide opportunities for those reporting to you to initiate their own ideas, questions, suggestions, proposals, criticisms and concerns to you? (Extremely High Degree of Opportunity, High Degree, Moderate Degree, Low Degree, Little or No Opportunity)

How often do you think you nurture an open door policy for communication with your employees? (AA, $\mathrm{VO}, 1 / 2, \mathrm{O}, \mathrm{NAN})$

\section{Dimension: Upward Permissiveness}

About how frequently do you have the opportunity to give additional ideas or information to your immediate supervisor over and above what he/she has asked for? (AA, VO, 1/2, O, NAN)

How often do your superiors provide you the opportunity to discuss the reasons for orders, instructions, or policies so you can understand why they are important? (AA, VO, 1/2, O, NAN)

\section{Dimension: Lateral Permissiveness}

To what degree does upper level management encourage its employees to initiate ideas, questions, suggestions, feedback, etc, with their peers?

$(\mathrm{AA}, \mathrm{VO}, 1 / 2, \mathrm{O}, \mathrm{NAN})$ 
How often do you find occasion to discuss work-related performance issues with others of your own rank in the organization? (AA, VO, 1/2, O, NAN)

\section{Competency: Responsiveness}

\section{Dimension: Downward Responsiveness}

In general, do you obtain prompt answers from questions and suggestions sent upward? (AA, VO, 1/2, $\mathrm{O}$, NAN)

How satisfied are you with the speed of feedback you generally receive from upper levels of management relative to a question you have raised? (Extremely Satisfied, Very Satisfied, Satisfied About Half the Time, Occasionally Satisfied, Not Satisfied)

\section{Dimension: Upward Responsiveness}

How reluctant are employees in providing straight forward answers to questions asked by upper levels of management regarding a crisis in the work setting due to fear of repercussions? (Extremely Reluctant, Very Reluctant, Moderately Reluctant, Occasionally Reluctant, Little or No Reluctance)

How comfortable do you think employees feel that they can ask questions of a sensitive nature to upper management? (Extremely Comfortable, Very Comfortable, Mixed Feelings, Occasionally Comfortable, Never or Almost Never)

Dimension: Lateral Responsiveness

How would you evaluate the willingness of your peers to provide you with information you have requested? (Extremely Willing, Very Willing, About Half and Half, Occasionally Willing, Never or Almost Never Willing)

How would you evaluate the accuracy of work-related information exchanged among your peers in this organization (In your Department)? (Extremely High Accuracy, Very Accurate, Moderate Level of Accuracy, Only Occasionally Accurate, Never or Almost Never Accurate?)

\section{Competency: Interdependence}

Dimension: Downward Interdependence

To what degree are your successful accomplishments as a manager related to the communication exchanges that you have with those you supervise? (Extremely Important to My Success, Great Importance, Modest Importance, and Low Importance, Not Very Important to My Success)

To what degree do you feel daily face- to- face interchange of information with those you supervise is important to your success as a manager? (EIMS, GI, MI, LI, NVIMS)

\section{Dimension: Upward Interdependence}

To what degree are your accomplishments as an employee dependant on having communication interchanges with your immediate supervisor? (Very Often, Often, About Half and Half, Not Often, Little or No Communication is Necessary)

How often do you feel there is a need to communicate with your immediate supervisor to perform your job in an effective manner? (VO, O, AH\&H, NO, LNC) 


\section{Dimension: Lateral Interdependence}

To what degree do you feel that your success on the job is related to the communication interchanges you have with your peers? (Extremely Important, Very Important, About Half and Half, Not Very Important, Little or No Importance)

How often do you feel there is a need to communicate with your peers in order to be successful on the job? (EI , VI,1/2, NVI, LNI)

\section{Competency: Reward for Communicating}

\section{Dimension: Downward Reward}

As a supervisor, how often do you experience a positive reward or payoff in this company for trying to improve your communication with those being supervised? (Very Often, Somewhat Often, About Half the Time, Seldom, Little, if Any).

Indicate how true you feel this statement describes your company: "As a supervisor of employees, my company seldom gives me recognition for trying to improve the communication with my employees." (Extremely True, Very True, About Half the Time, Seldom True, Little if Any Truth in This Statement)

\section{Dimension: Upward Reward}

I feel there is a positive payoff for me when I communicate to upper management what's going wrong on the job that impacts my performance. (Extremely Positive Payoff, Very Positive Payoff, About Half The Time, Seldom A Positive Payoff. Little or None)

To what degree does this statement relate to your work environment? "Upper management most of the time only wants to hear positive information from us. There is no value to communicate what's going wrong to them.” (Statement Generally Reflects Managements’ Attitude, Generally Does Not Reflect Managements' Attitude)

\section{Dimension: Lateral Reward}

How true is this statement in your work setting? : "My peers feel there is a positive payoff to keep me informed about things that can improve my performance." (True Statement, Partially True, Not a true statement.)

My peers feel that they are encouraged by upper management to share information openly with others at their level. (TS, PT, NTS)

\section{Competency: Trust}

\section{Dimension: Downward Trust}

As a manager, what is the degree of trust you think you have with those you supervise in sharing ideas and sensitive information with them? (Extremely High Trust, Great Deal of Trust, Modest Level of Trust, Low Level of Trust, Little if Any Trust)

To what degree do your superiors encourage you to establish trust with those you supervise? (Very Often, Often, Occasionally, Rarely, No Encouragement)

Dimension: Upward Trust

How much trust do you think exists among subordinate levels when they have a need to share sensitive 
information with those that supervise them? (Extreme Trust, Great Deal of Trust, Moderate Trust, Low Trust, No Trust)

To what degree do employees feel upper levels of management are making a sincere effort to establish trust with those they supervise? (Extremely Sincere Effort, Very Sincere Effort, Occasionally, Minimum Effort, No Effort)

\section{Dimension: Lateral Trust}

How much trust do you think exists among your peers when sharing work-related information? (Extreme Trust, Great Deal of Trust, Moderate Trust, Low trust, Little or No Trust)

How would you describe your comfort zone in expressing your work related feelings with your peers? (Extremely Comfortable, Very Comfortable, Occasionally Comfortable, Low Level of Comfort, Little if Any Comfort)

The above questions are offered only as ideas for those who have the desire to develop a Macro Communication Audit. It is recommended more than two questions be asked for each dimension of a core communication competency. In order to obtain a 360 degree assessment, questions should be asked not only of managers, but also should be asked of their employees, peers, upper management, and even clients (customers). Recommended reading for those intending to develop an organizational communication audit on a large scale is Owen Hargie and Dennis Tourish's book on Auditing Organizational Communication. ${ }^{6}$

\section{SUMMARY}

The organizational communication core competencies and dimensions of communication discussed above can provide consultants, researchers and managers with a framework to customize questions as they relate to specific work environments. The sample questions provided are offered to demonstrate how specific competencies and dimensions can be addressed by utilizing them in multiple research tools such as questionnaires surveys, interviews, focus groups, or in workshop settings. The numbers of questions, length of the audit instrument, methodology employed and sample size will, of course, depend on the outcome expectations of the client organization.

For organization-wide communication audits, all questions developed should be field tested with a sample of subjects similar to those who will be involved in the actual audit. This is recommended to determine the efficacy of each question, and to assess the semantics/structure/composition of each question prior to administering the actual audit.

Developing and administering communication audits will assist an organization to identify its internal communication strengths and communication barriers that can impede an organization from having effective vertical and lateral communication. With the rapid changes impacting organizational structures, it is recommended that communication audits be included in the strategic planning of complex organizations, and be administered every three to five years. The overall results of an extensive communication audit can identify the degree of communication satisfaction existing within a specific work unit or within an entire organization.

\section{AUTHOR INFORMATION}

Dr. Minter is currently Executive Vice President and Chief Academic Officer and professor at Walsh College, Troy, MI. He has been a Dean of Business Colleges at: Delaware State University, Texas Wesleyan University, Cleveland State University, University of Northern Iowa, University of Michigan-Dearborn and Central Connecticut State University. He has a Ph.D. in Organizational Communication and Industrial Relations from Purdue University. Both his Master of Arts and Bachelor of Arts Degrees are from Miami University of Ohio. 


\section{FOOTNOTES}

1. Breth, Robert (1952). "Human Relations and Communication Are Twins," Personnel Journal, XXXI (December), 161.

2. Klein, Howard J., Baker, Thomas E., Meyer, John P., (2009). Commitment in Organizations. Routlidge Taylor and Francis Group: New York, 288-289.

3. Gibb, Jack, (1961). "Defensive Communication," Journal of Communication XI (September) 141-148; Also see by the same author, "Fear and Façade: Defensive Management" in Science and Human Behavior. Books Inc.: Palo Alto, California, 1965, 198-214.

4. $\quad$ Klein, et al. Commitment in Organizations. op.cit. 288-289.

5. Some of these concepts appear in W. Charles Redding, Michael Sincoff, (1984). The Corporate Manager's Guide to Better Communication. Scott, Foresman, PROCOM Series: Glenview; Illinois.

6. Hargie, Owen and Tourish, Dennis, eds., (2009). Auditing Organizational Communication: A Handbook of Research, Theory and Practice. Routlidge, Taylor and Francis Group: New York. 
EXHIBIT 1:

Organizational Communication Competencies \& Dimensions of Communication

\section{Organizational \\ Communication \\ Competencies}

Influence

Feedback

Receptiveness

Interdependence

Reward for Communicating

Trust

\section{Downward Communication \\ (supervisor to subordinate)}

Downward influence measures the degree supervisors feel they can obtain desired responses from employees.

Downward Receptiveness measures the degree managers are willing to receive feedback from employees that relate to previous communications. Also to what degree does management make use of the feedback received from employees.

\section{Downward Permissiveness} measures the degree managers perceive they encourage employees to initiate their own ideas, questions, suggestions, proposals, criticism, and reports to upper levels.

\section{Downward Responsiveness} measures the degree managers provide feedback to messages directed to them from employees.

\section{Downward Interdependence} measures the degree managers perceive that their accomplishments are related to the communication interchanges that they have with their employees.

Downward Reward measures the degree managers perceive that there is a reward or positive payoff for improving downward communication with employees.

Downward Trust measures the degree managers trust those they supervise to share ideas/sensitive information with them.

\section{Upward Communication (subordinate to supervisor)}

Upward Influence measures the degree employees feel they are able to obtain desired responses from their managers.

Upward Receptiveness measures the degree to which employees are willing to receive feedback from their managers.

\section{Upward Permissiveness} measures the degree employees perceive that they are encouraged by management to initiate ideas, questions, suggestions, etc. to upper management.

Upward Responsiveness measures the degree employees provide feedback to messages initiated by their managers.

Upward Interdependence measures the degree employees perceive that their accomplishments are related to the communication interchanges they have with their managers.

Upward Reward measures the degree employees feel there is a reward or positive payoff for them to communicate upward to their managers.

Upward Trust measures the degree of trust employees have in those who supervise them when having to share ideas/sensitive information with upper level managers.

\author{
Lateral/Horizontal \\ Communication \\ (peers)
}

Lateral Influence measures the degree

employees feel they are able to obtain desired responses from their peers.

\section{Lateral Receptiveness} measures the degree to which employees are willing to receive feedback from their peers.

\section{Lateral Permissiveness} measures the degree employees perceive that they are encouraged by management to initiate ideas, questions, suggestions, feedback, etc. with their peers.

\section{Lateral Responsiveness} measures the degree employees provide feedback to messages they receive from their peers.

\section{Lateral Interdependence} measures the degree employees perceive that their accomplishments are related to the communication interchanges they have with their peers.

Lateral Reward measures the degree employees feel there is reward or positive payoff

for them to engage in communication with their peers.

Lateral Trust measures the degree of trust employees have in sharing ideas and/or sensitive information with their peers. 


\section{EXHIBIT 2:}

\section{Organization Communication Climate Profile (OCCP)}

Directions: Refer to Exhibit I for definitions of the following organizational communication competencies listed in the left hand column. Then, evaluate dimensions "A," "B," and "C" in terms of your own organization or work unit using the Communication Climate Satisfaction Scale below. Insert scale values for each of the following competencies in terms of your own perceptions of the downward, upward and lateral flow of communication within your organization.

\section{Communication Climate Satisfaction Scale:}

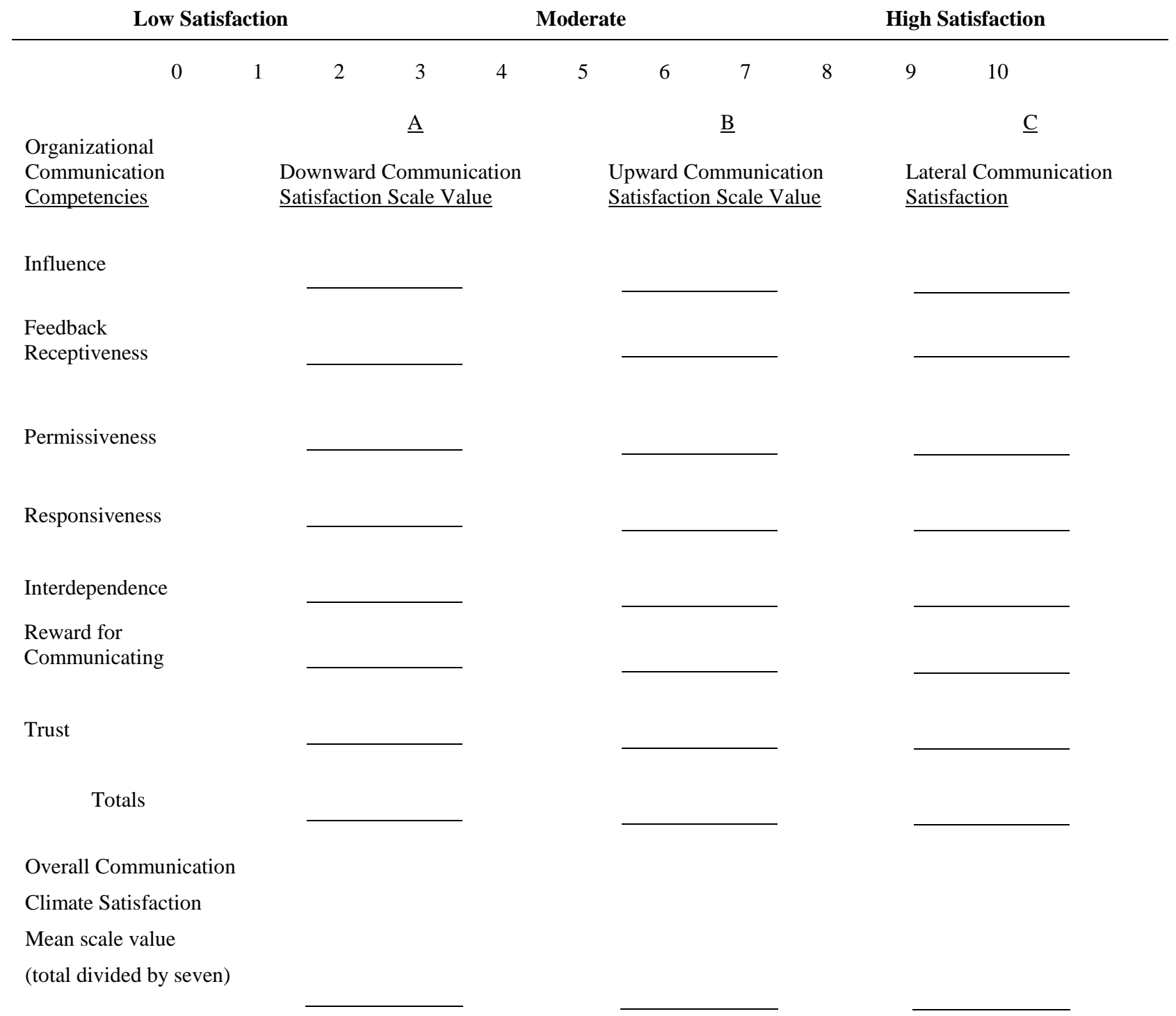

R.L. Minter, Ph.D.

Walsh College, Troy, MI 